Article

\title{
Ageing in Place in Disaster Prone Rural Coastal Communities: A Case Study of Tai O Village in Hong Kong
}

\author{
Crystal Kwan *(D) and Ho Chung Tam (D) \\ Department of Applied Social Sciences, Hong Kong Polytechnic University, Hong Kong; \\ ho-chung.tam@polyu.edu.hk \\ * Correspondence: cyeekwan@polyu.edu.hk; Tel.: +852-3400-3681
}

Citation: Kwan, C.; Tam, H.C.

Ageing in Place in Disaster Prone Rural Coastal Communities: A Case Study of Tai O Village in Hong Kong. Sustainability 2021, 13, 4618. https:// doi.org/10.3390/su13094618

Academic Editor: John T Cooper

Received: 25 March 2021

Accepted: 17 April 2021

Published: 21 April 2021

Publisher's Note: MDPI stays neutral with regard to jurisdictional claims in published maps and institutional affiliations.

Copyright: (c) 2021 by the authors. Licensee MDPI, Basel, Switzerland. This article is an open access article distributed under the terms and conditions of the Creative Commons Attribution (CC BY) license (https:// creativecommons.org/licenses/by/ $4.0 /)$.

\begin{abstract}
Rural coastal communities face unique disaster risks that will impact interventions throughout the disaster risk reduction (DRR) cycle (mitigation, preparedness, response, and recovery). At the same time, these communities are experiencing an ageing population. As climate change contributes to rising sea levels and an increase in the intensity and frequency of climate-related disasters, older populations living in rural coastal communities face heightened risks. This is a qualitative case study examining the ageing in place (AIP) experiences of older people living in a disaster-prone rural coastal community in Hong Kong-Tai O Village. Findings highlight that: (i) a critical dimension of AIP is their ability to sustain and continue their work, which played a multidimensional role, (ii) local community-based organizations play an instrumental role in providing social support in a disaster context, (iii) more support and resources for mitigation activities are needed, and (iv) while supports exist for AIP and in a disaster situation, the older residents may not utilize such supports. In addition to informing age-friendly DRR programmes and research, these findings inform AIP practices, policies, and research relevant to rural coastal communities.
\end{abstract}

Keywords: ageing-in-place; disaster-prone; rural and coastal communities; Hong Kong; qualitative study

\section{Introduction}

\subsection{Rural Coastal Communities at the Forefront of Population Ageing}

"The world's older population is growing in absolute and relative terms" [1] (p. 5). In 2019, there were 703 million older people (aged 65+). By 2050, that number will triple to reach just over 1.5 billion older people (United Nations, 2019). Rural coastal communities are areas that are at the forefront of population ageing due to the out-migration of younger age groups to urban and inland areas for education and job opportunities, as well as lower birth rates, longer life expectancies, and the in-migration of retirees [2-5]. Ageing in place (AIP) generally refers to empowering older people to remain living, with a level of independence, in the community as they age rather than in institutional care [6]. It is a popular concept adopted in current ageing policies because it is a less costly alternative to institutionalized care and attunes to older people's increasing preferences to age and live independently in their own home/community [6].

Since the 1990s, when AIP first gained attention through Lawton and colleagues' early seminal work [7-9], the discourse on AIP continues to grow [10]. Vasunilashorn and colleagues [10] conducted a systematic literature review documenting this concept's evolution within gerontological literature. They found that while initially AIP focused primarily on the physical environment matching the physical capabilities of aging populations, it has evolved to include considering other dimensions, such as technology, services, social supports, and health factors associated with older people's ability/inability to AIP. Importantly, they posit, "aging in place is not a one-size-fits-all concept. There are multiple issues surrounding differences in aging in place among diverse populations" (p. 4). They 
further contend that differences occur due to, for example, geographical locations (urban vs. rural), income, sexual orientation, cultural context (e.g., eastern vs. western views on aging), and circumstances and needs of older people (e.g., older adults with developmental disabilities and older adult caregiving for children with developmental disabilities).

Aging populations living in rural coastal communities are particularly prone to climate change and natural disasters, and they usually lack development options [11]. Rural coastal communities can be defined as communities living on the land alongside the sea, primarily dependent on natural resources for livelihoods [12]. These communities are also less frequently included than their urban counterparts in adaptation and mitigation planning and policies [13]. Rural coastal communities have unique strengths and challenges that implicate AIP. For instance, evidence suggests that older people living in rural coastal communities experience greater social exclusion and isolation, limited access to health and other community services, greater financial difficulties (e.g., related to fuel poverty and housing issues), and lack of transportation options compared to their urban counterparts [14]. In contrast, the following are positive factors that foster AIP for older people living in rural coastal communities: enhanced community networks, family support and informal care, and "environmental factors such as less crime and more green space" [14] (p. 4). One key challenge facing such populations to AIP, which is largely unexamined in policy and research discourse, is the impacts of climate change and specifically the increase in the intensity and frequency of climate-related disasters (e.g., typhoons, storm surges, floods).

\subsection{Rural Coastal Communities at the Frontline of Climate Change}

The Intergovernmental Panel on Climate Change (IPCC) [15] reported that the global mean sea level [GMSL] is rising and accelerating. Coastal communities are increasingly exposed and vulnerable to sea level rises and more intense and frequent extreme sea-level events (e.g., flooding, storm surges, tropical cyclones, coastal erosion, and salinization). From 2005-2015, GMSL increased to $3.6 \mathrm{~mm} / \mathrm{yr}$, a rapid increase from 1901-1990 that experienced only a $1.5 \mathrm{~mm} / \mathrm{yr}$ rise. Furthermore, if greenhouse gas emissions are not mitigated, GMSL is projected to rise by $0.61-1.10 \mathrm{~m}$ by 2100 . However, the IPCC stated that "a rise of two or more meters cannot be ruled out" (p. 411). Many coastal communities will need to retreat, and low-lying small island states may even completely disappear within the next 80-100 years. Compared to their urban counterparts, rural coastal communities are also disadvantaged when it comes to mitigation efforts. Jurjonas and Seekamp [16] posit that urban coastal communities have a stronger capacity to adapt due to their more substantial tax base from the flow of tourism dollars, high-value properties, and strong industries. Furthermore, rural coastal communities typically have higher poverty rates [17]. Poor households are at the greatest disadvantage as they cannot afford to adopt mitigation efforts to protect them from rising sea levels and other coastal hazards.

\subsection{Ageing in Place within the Context of Disaster-Prone Rural Coastal Communities}

To the authors' knowledge, there are only a few published peer review studies examining AIP within the context of disaster-prone rural coastal communities. For instance, Astill and Miller [18] examine cyclones' impact on the Far North Queensland coastal communities' aging population. They found that this older population has low self-efficacy in the context of disasters (e.g., disaster recovery) and is increasingly needing to rely on government authorities' support. However, such support is limited, thus implicating this populations' considerations of AIP. As a result, the authors suggest the need for better emergency management regarding AIP planning for remote coastal areas and specifically in promoting the older population's self-efficacy and their communities. Bukvic et al. [19] assessed and compared the age-related vulnerabilities of older populations in rural and urban flood-prone coastal communities on the U.S. East Coast. The authors found that in the rural contexts, the aging populations are more likely to have "older housing stock, disabilities, and lower-income," which further increases their disaster risk compared to 
their urban counterparts (p. 1). Additionally, this study also found that the impacts of rising sea levels and chronic flooding events are usually neglected in disaster resilience policy. The focus is generally on major acute disasters, even though the former is a more recurrent and common event that implicates the older population's AIP ability.

\subsection{Knowledge Gap and Situating This Study}

The implications of disasters to AIP were not mentioned in Vasunilhashorn et al.'s [10] review, and no studies were found that examined AIP within disaster-prone communities. Kwan and Walsh [20] conducted a more recent review focused on the state of knowledge regarding disaster resilience with older adults (not specifically on AIP). The authors found limited studies examining the intersections between older adults/ageing and disasters. Furthermore, understanding AIP within the context of disaster-prone rural coastal communities is even more limited, despite the popularity of AIP in policy and research discourse and the increase in aging populations in such contexts [4]. This study addresses this knowledge gap by providing the findings from an exploratory qualitative study examining AIP experiences and perspectives among older people living in a disaster-prone rural coastal community-Tai O Village, Hong Kong. Specifically, the research questions are:

(1). In what ways are the older residents (65+) attached to Tai $\mathrm{O}$ village as a place to age?

(2). What are the facilitators and challenges to age in place for these residents?

(3). How do disasters impact aging in place for these residents?

(4). What supports do they access and use to reduce the impacts of disasters?

\subsection{Conceptual Framework: The Disaster Risk Reduction Cycle}

The Disaster Risk Reduction (DRR) Cycle is a popular framework to examine individuals, families, communities, and societies' capacity to adapt and recover from hazards/shocks [21,22]. The DRR cycle includes resilience-building activities through predisaster (mitigation and preparedness) and post-disaster (response and recovery) phases [21]. Mitigation refers to long-term strategies and activities focused on capacity building to prevent and reduce the negative impacts of disasters. Wider development initiatives, such as building disaster-resilient structures (physical infrastructures) or social protection programs (social infrastructures), are examples of mitigation activities. In contrast, preparedness is more narrowly focused on responding effectively and efficiently in the immediate aftermath of a disaster. The development of emergency kits and evacuation plans are examples of preparedness activities. Response refers to implementing the preparedness activities when a disaster has occurred (are more short-term focused). Examples of such activities include evacuation processes and shelters, search and rescue operations, and relief goods distribution (e.g., water, food, and medicines). Recovery is long-term focused. Such efforts include rebuilding to a "new normalcy" and ensuring that improvements have been made to reduce vulnerabilities in the face of upcoming disasters. Examples include improving facilities, livelihoods, and living conditions.

These phases of the DRR cycle do intersect and are not mutually exclusive. A key premise of this framework is that disasters are intimately connected to the conditions and structures during pre-disaster times, and the negative impacts of a disaster are a result of existing gaps and vulnerabilities in the physical and social infrastructure at the household, community, and societal level. While this framework is used often in the disaster literature, it can also be used to understand AIP within disaster-prone rural communities.

\section{Materials and Methods}

Ethics approval was obtained from the Human Subjects Ethics Sub-committee (HSESC) at the Hong Kong Polytechnic University (Reference \#HSEARS20190502001). A qualitative case study research design $[23,24]$ was used. 


\subsection{Study Site: Tai O Village in Hong Kong}

The Comprehensive Social Security Assistance Scheme (CSSA) and Social Security Allowance Scheme have been the significant foundations of Hong Kong's social security system in the last 40 years, serving as the financial aid for the most marginalized in society, including older adults. The Government of Hong Kong (GovHK) set up the Elderly Commission in 1997 and has implemented several policies and services to promote AIP, such as housing, home and community care, financial security, health and medical, psychological, employment, and recreational sectors.

The GovHK also provides funding for non-governmental organizations to conduct AIP services, albeit the majority of the services are in urban contexts. For example, the Hong Kong Housing Society has launched the Ageing in Place Scheme in all 20 rental estates since 2012 to support older adult tenants in housing, social care, and health care. With more than one-third of tenants aged over 60, the Society offers discounted rent to older adult tenants in nine of its estates, all located in the city/urban context.

The Age-Friendly City (AFC) initiatives that began in 2010 in Hong Kong are also key examples of the GovHK's AIP policies.

In our study site, Tai O, AFC has been promoted jointly by the government and social enterprises such as The Hong Kong Jockey Club Charities Trust ("The Trust"). "The Trust" launched the Age-Friendly City Project in Tai O with the YWCA between 2017 and 2018, aiming to address older Tai $\mathrm{O}$ residents' home safety. Waterfront promenades and outdoor seating areas near residential areas in Tai $\mathrm{O}$ were built. Community events were also organized to enhance social participation and inclusion for older adults.

Located on the western part of Lantau Island in Hong Kong, Tai O is one of the existing fishing villages in Hong Kong. Historically, Tai O was a hub of connecting Hong Kong with Macau and the Pearl River Delta. The ecology and geographical location of Tai O facilitated the development of fishery, agriculture, salt making, and trading. As the home for coastal communities for more than 200 years, the residents of Tai $\mathrm{O}$ developed their own culture and tradition, making themselves one of the indigenous communities in Hong Kong. Since the 1960s socioeconomic transformation in Hong Kong, primary production industries have ceased to exist. Many of the residents and new generations moved to settle in urban regions for school and work, resulting in less than 3000 residents currently living in Tai O [25].

The residents of Tai $\mathrm{O}$ can be distinguished into two groups: onshore residents who work in agriculture, salt making, and trading, and offshore residents or boat dwellers who work in the fishery and live on boats or in stilt houses. Stilt houses are the traditional houses built by Cantonese fishermen to replace living in the limited space on boats and provide a safer environment for the family. They serve as a place of residence, but stilt houses are also workplaces and shops for fishermen trading fishery harvests. The front areas of every stilt house are connected with planks and stakes. It is the central passage between stilt houses and residents gathering, reflecting the close physical and social relationship between the stilt houses and their neighbors.

Tai $\mathrm{O}$ is a remote rural area about $25 \mathrm{~km}$ from Tung Chung, the city center of Lantau Island, where Lantau Island's main hospital is. There are limited facilities such as general outpatient clinics, fire stations, and community centers in terms of infrastructure. Yet, the roads in Tai $\mathrm{O}$ are small and narrow, and light ambulances and light fire appliances or helicopters are usually used for an emergency in the area. Tai $\mathrm{O}$ is a low-lying coastal area, making it more prone to rising sea levels and floods and primarily has an ageing population [26]. It was also directly impacted by two major disasters in the last 4 years, Super Typhoon Hato in August 2017 and Mangkhut in September 2018. Figure 1 showcases the stilt houses in Tai O Village. 


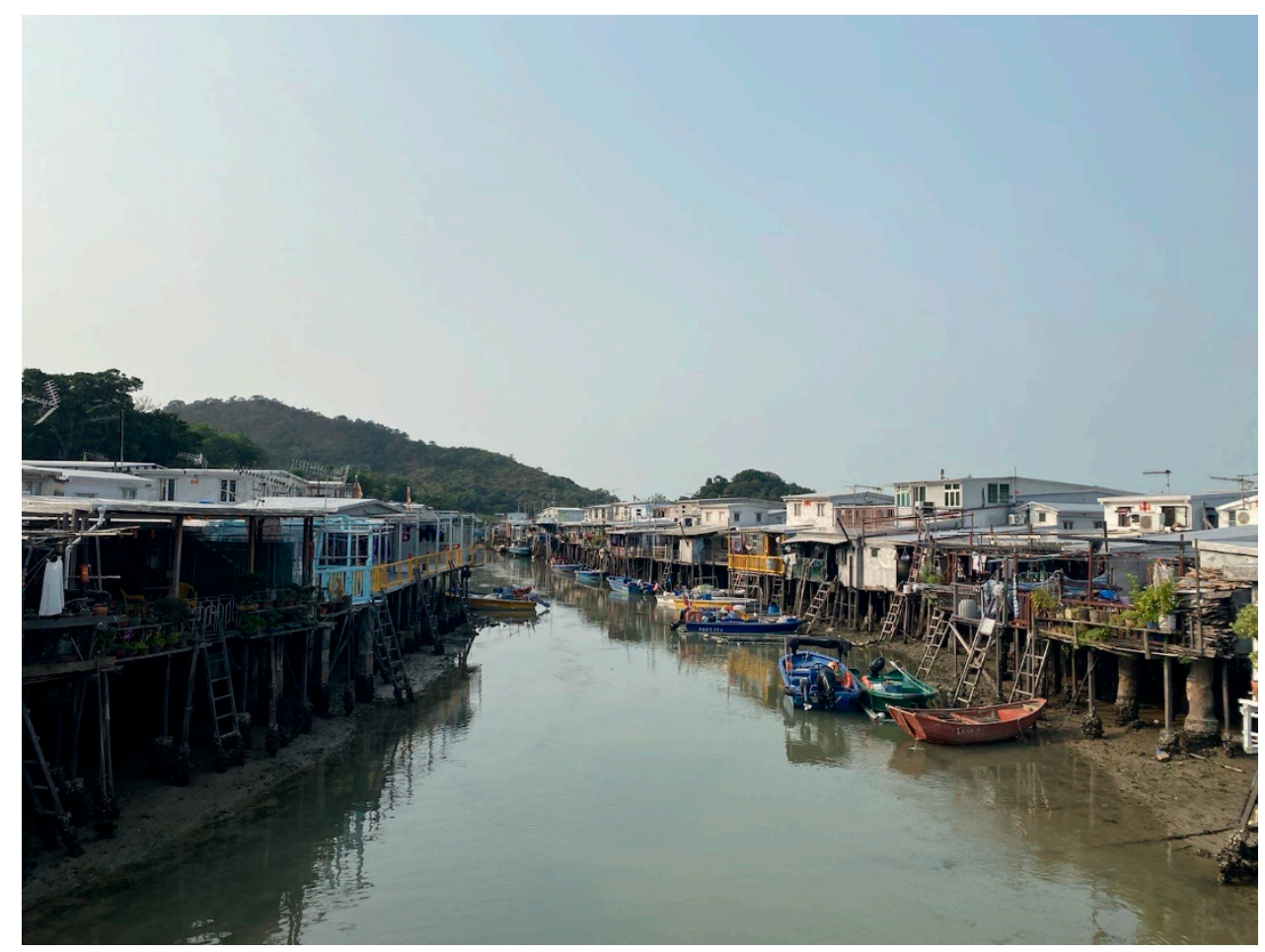

Figure 1. Stilt Houses in Tai O.

\subsection{Recruitment and Sample}

Purposive and snowball sampling was used to recruit 12 participants. Participants were recruited through two essential means. The first was through visiting and initiating conversations in the communities. Second, a local non-governmental organization (NGO) that provides resilience-building programs and services against climate disasters to Tai $\mathrm{O}$ residents also helped recruit participants by sharing information about the project with their service-users.

Criteria used for participants' selection were: (i) 65 years of age and older, (ii) lowincome, (iii) having at most a grade six education, and (v) living in Tai O Village. Lowincome was defined as below the "poverty line", the official policy tools set by the GovHK, which is measured as $50 \%$ of the median monthly household income before policy intervention such as taxation and social welfare transfers. According to the most recent statistics, the poverty lines by household size in 2019 were: [HKD] $\$ 4500$ for 1-person; $\$ 10,000$ for 2-person; $\$ 16,600$ for 3-person; $\$ 21,400$ for 4-person; $\$ 22,100$ for 5-person; and $\$ 23,000$ for 6-person and above [27] (p. viii). The sample was limited to older people who are low income and have lower education levels to focus on the most marginalized and underserved older people living in rural coastal communities. There is evidence to suggest that lower socioeconomic status is associated with greater vulnerability in a disaster context [28] and barriers to AIP $[29,30]$. To provide context, 18\% (about 1.4 million) of the Hong Kong population is 65+ [31]. Additionally, about 32\% of Hong Kong's low-income population are older adults $(65+)$. Regarding education, only $14.9 \%$ of the total population in Hong Kong has lower than a secondary education level [32].

\subsection{Data Collection and Analysis Methods}

Data was collected using semi-structured interviews, which were carried out between July 2019 and January 2020. Single-session interviews of $30 \mathrm{~min}$ to $1 \mathrm{~h}$ long were conducted with the participants. The interviews were mainly carried out at the participants' workplaces, which were their homes (shophouses that operated businesses right in front of their homes). One of the interviews was carried out in the local NGO's community center. All interviews were audio-recorded, translated, and transcribed, and thematic analysis [33] 
was applied to the data. A hybrid approach to coding [34], which included both deductive and inductive codes, was adopted, and both authors were involved with the analysis. The deductive codes included codes related the phase(s) of the disaster risk reduction cycle (mitigation, preparedness, response, and recovery) and the literature (e.g., social participation and health/mobility were predetermined codes as they are important factors influencing aging-in-place). Inductive codes were created if the data were relevant to aging in place but could not be coded into the pre-determined codes. These codes were then re-organized (including combining or separating codes and creating subcodes) into themes (and sub-themes) that would answer the research questions. Sub-themes were created when there were nuanced perspectives related to a specific theme that helped to explain the multi-dimensionality of the theme. To ensure consistency and rigor among the coders, the authors first independently coded the first three transcripts then came together to compare and resolve discrepancies between their codes. A codebook [35] was developed based on the discussion highlighting the names, descriptions, examples, and counter-examples of the initial codes. For the remaining transcripts, the second author conducted the initial coding, updating the codebook after each transcript when necessary (e.g., identifying new codes that emerged). The first author reviewed the coding and codebook, and meetings were arranged when any discrepancies needed to be resolved between the two analysts. Figure 2 outlines the data analysis process.

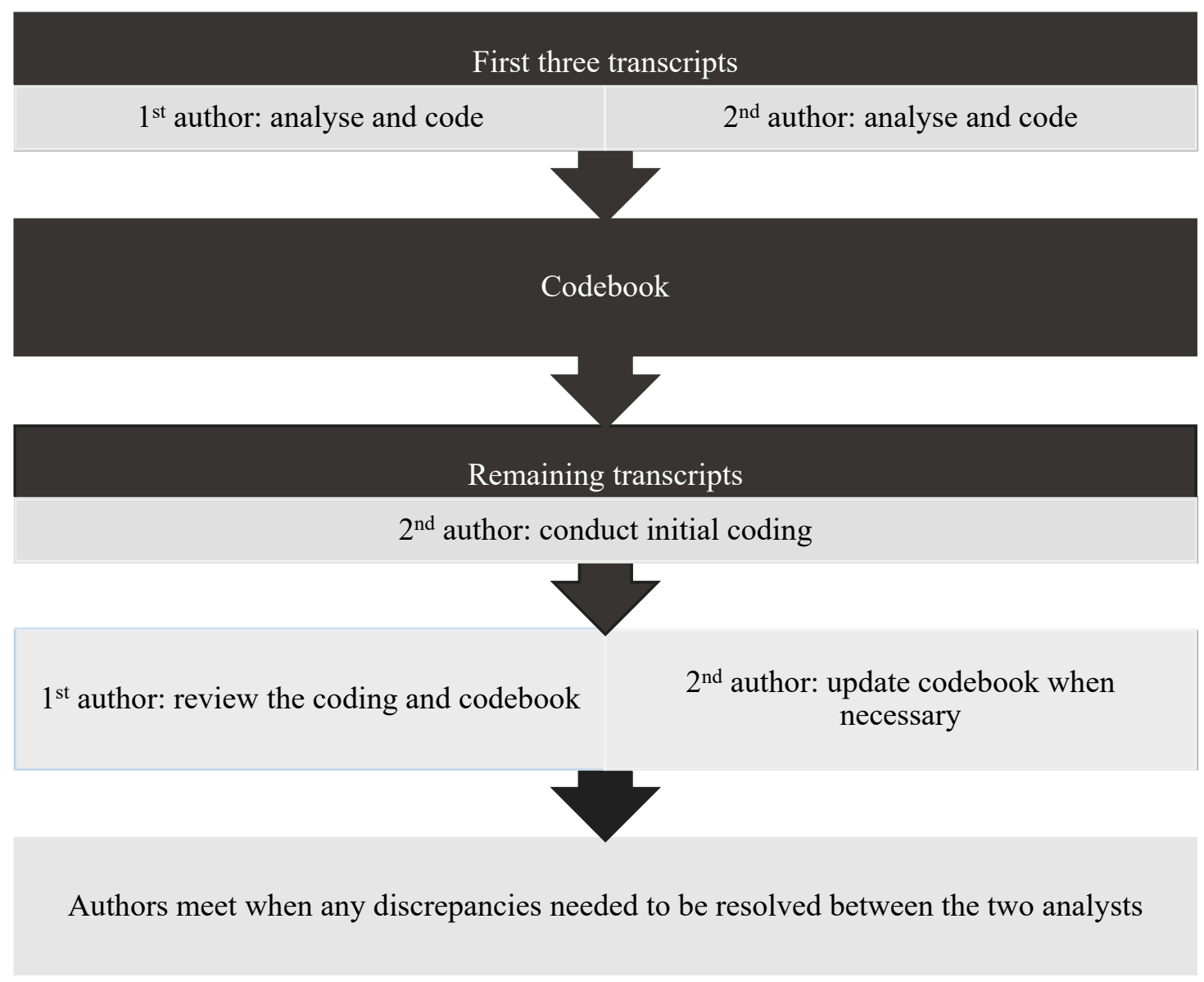

Figure 2. Data analysis Process. 


\section{Results}

3.1. Research Question \#1: In What Ways Are the Older Residents (65+) Attached to Tai O Village to Age in Place?

Theme: Attachments to Tai O Village Were related to Their Ancestral Homes, a Close-knit Community Lifestyle, and Lower Costs of Living

The participants expressed various reasons why they were attached to Tai $\mathrm{O}$ as a place to age, including living in their ancestral home, being accustomed to a close-knit community's lifestyle (e.g., knowing your neighbors and feelings of safety), and having lower costs of living. Most $(n=8)$ of the participants live in stilt houses, right on the waterfront. These stilt houses are ancestral homes and were built and lived throughout multiple generations (e.g., 3-4 generations). For instance, a participant who is 86 years old shared, "yes, we built this [stilt house] by ourselves. About 30 to 40 years [old]. I can't remember exactly. I lived in this house since I was born. We have three or four generations here in this house". Table 1 outlines the participant characteristics.

Table 1. Participant characteristics.

\begin{tabular}{|c|c|}
\hline & Participants $(n=12)$ \\
\hline \multicolumn{2}{|l|}{ Gender } \\
\hline Female & 9 \\
\hline Male & 3 \\
\hline \multicolumn{2}{|l|}{ Age } \\
\hline Young-old (65-74) & 5 \\
\hline Middle-old (75-84) & 5 \\
\hline Old-old $(85+)$ & 2 \\
\hline \multicolumn{2}{|l|}{ Place of birth } \\
\hline Hong Kong & 11 \\
\hline Macau & 1 \\
\hline \multicolumn{2}{|l|}{ Language spoken } \\
\hline Cantonese & 12 \\
\hline \multicolumn{2}{|l|}{ Living arrangements } \\
\hline With spouse & 7 \\
\hline With spouse and kin & 3 \\
\hline With friends and other & 2 \\
\hline \multicolumn{2}{|l|}{ Housing type } \\
\hline Privately-owned houses & 12 \\
\hline Subsidized public housing & 1 * \\
\hline \multicolumn{2}{|l|}{ Marital Status } \\
\hline Married & 10 \\
\hline Single & 1 \\
\hline Widowed & 1 \\
\hline \multicolumn{2}{|l|}{ Education level } \\
\hline No formal education & 7 \\
\hline Less than primary (less than six years) & 3 \\
\hline Primary & 1 \\
\hline Secondary & 1 \\
\hline \multicolumn{2}{|l|}{ On government social assistance } \\
\hline SSA Scheme & 11 \\
\hline OPS & 1 \\
\hline
\end{tabular}

Growing up in Tai $\mathrm{O}$ and being accustomed to the lifestyle in a close-knit community was shared as another reason why Tai $\mathrm{O}$ was home for most $(n=10)$ of the participants. One individual shared, "usually, the older people who grew up here would stay in Tai $\mathrm{O}$ [and] even though our children move to Hong Kong, we would not go with them. We don't get used to the living style in Hong Kong and the air quality. Go inside the flat and close the door. You cannot see anybody and stay alone at home". One participant (I10) also shared how she felt safe living in Tai O, "yes, I am happy to live here. It is not good to live 
in the buildings. I don't get used to it, and it is not convenient. You have to lock the door every time. Yes, it is different here. We could just close the door without locking it, only at night while sleeping".

Another reason for living in Tai $\mathrm{O}$ as a place to age was more at a practical level, whereby the costs of living are much lower than in the city. All the participants owned the stilt houses, but the land is leased for a small rental fee. As one participant mentioned, "the leasing fee for the land is very cheap". Albeit half the participants $(n=6)$ expressed how the fee is increasing and is getting more expensive.

\subsection{Research Question \#2: What Are the Facilitators and Challenges to Age in Place for Rural Coastal Older Residents?}

\subsubsection{Theme: "Work Is Inner Sustenance"}

All the participants were still working, and the work they did was connected to Tai $\mathrm{O}$ (e.g., caught, dried, and sold dried fish outside their homes or a small shop selling drinks and snacks outside their homes). It is important to note that all the participants expressed how their work was not their primary source of income (e.g., made very little income) and was instead significant to their physical, mental, and social well-being. For example, one participant shared, "yes. We like working and drying seafood. You know, when people stop working, they will age very quickly. So, working is like inner sustenance. You don't easily get bored if you have something to do. Some elders just do nothing, and you can see. Of course, our work couldn't make money. We all know that there aren't many things we could sell".

All the participants had flexibility in the times they worked, and this was expressed as an important component of their work, as one participant who was a fisherman explained, "I get knackered after a prolonged period of working. I am already at quite an old age. I enjoy taking a rest. It's my work. I control when I want to work [and] there is no rush. I just want to be happy. Sometimes I work for my things. But I don't want to work for other people. I have plenty of offers ... haha ... so working freelance suits me. I don't aim for abundance, I have enough for spending, and it's already very nice. It's important that I can control my time".

Another participant explained how her work enables her to also socialize and chat with neighbors, "we could not earn much ... it is just for spending time ... .I bought it at $\$ 310$ (referring to the seafood), but I sold it $\$ 320$. We cut it and [then] clean it. How could I make ends meet from selling few bags [of seafood] only? It is just for one or two people to look or talk. Otherwise, I would stay in the stilt house and open the air-conditioner. Open the T.V. We do not expect much. If we meet friends in the street, we have a causal talk".

Another participant mentioned how she does not keep track of her profits from her work, "haha! I never have a record of that! Anyway, I just have to sell them. If they are sold out, I will restock. If I don't have enough money for restocking, like beer, water, anything, I just buy on credit, and I pay later-when I have enough money. The suppliers don't mind. They allow me to buy on credit. I will repay when I restock again". However, one individual mentioned how old age is starting to prevent them from continuing some of their work activities, "but we would not do it anymore. We are old. We could not dry it. It is the last year that I could dry the fishes. Yes, the last year because I am old. I cannot do it".

\subsubsection{Theme: Social Participation}

When asked about what they did in their free time for leisure and social participation outside of work, some participants $(n=5)$ shared a few activities, which included: (i) going to the park and chatting with other older adults (e.g., "there are so many elders sitting in the park, sometimes I talk to other elders there when I am free"), (ii) taking walks (e.g., "we just hang around like walking and killing time after dinner. My husband and I walk along the promenade every night"); (iii) watching T.V. (e.g., "nothing special, I spend my time mostly on watching T.V., I love watching T.V. If I am not chatting with you, I would be 
watching Korean drama"); and (iv) having tea and dim sum with friends (e.g., "I go yum cha (a breakfast/brunch tradition of eating dim sum and having tea), I can meet my friends there. We chat there and sit there for like few hours, and I return home. The Chinese tea house opens at 6 a.m., and we are there around 5 a.m.!").

Less regular or frequent activities were shared by most participants $(n=7)$, including traditional festive holidays like Lunar New Year and Ching Ming Festival (a day to remember the ancestors and activities would include sweeping and cleaning the tombs) and watching traditional Cantonese Opera at the Tai O theatre. However, the participants expressed that these opportunities for social activities and engagement are becoming relatively less than before; as a participant explained, "there are a lot of residents of Tai $\mathrm{O}$. Every Ching Ming festival, a lot of people come back. If you want to know how big the population [of Tai O] is, you should visit during the festival. Only the offspring of the Tai O residents will come back. It is even more crowded than Lunar New Year, but comparably now there are fewer people, as there is a long holiday, people will avoid coming back on the exact day. Some people will also go on travel during the long holiday".

\subsubsection{Theme: Health/Mobility Issues and Living in Stilt Houses}

The stilt houses that the participants lived in are all two-story, wherein the first floor was usually the workplace and "home" area, and the second floor was the bedroom. A participant explained the rationale for this layout, "I live on the second floor, upstairs of my shop. If the flood gets up to where I live, it would be a large problem!" To get to the second floor, most of the participants must climb a steep staircase or, in some cases, a ladder. Furthermore, half of the participants $(n=5)$ expressed how they have mobility issues. One of the participants shared how she has edema on her leg, and she has to climb up and down daily to her second floor, "yes, I have to climb up and down. My legs have some problems. I can't really walk". Another participant shared how a past injury in her leg continues to impact her mobility today, "I had my leg broken before. I have to go with a cart (walking aids). Without a cart, I could not walk with the assistance of an umbrella only. The doctor said, 'you need to be careful. Your bone will be broken if you have an accident again.' We had a hard time in the past. It impacted our health. No good care when I was young. It gets more serious when I am old now". Another participant shared how she used to go to the city more often, but due to mobility issues, she has stopped. "No, I don't go into the city anymore. I am old now. I went there quite frequently in the past. I can barely walk now".

\section{Sub-Theme: Need to Travel to the City for Health Services}

When asked about where they go to seek health services, a few of the participants $(n=3)$ shared that they would travel to the government hospital in Tuen Mun or Tung Chung, both are districts in the city that takes approximately $1-2 \mathrm{~h}$ to reach by public transport (bus) from Tai O. A participant explained how services are cheaper at the government hospitals, "we could enjoy medical benefits and have Health Care Vouchers (referring to the Elderly Health Care Voucher scheme for older persons 70+ in Hong Kong that provides subsidies for medical expenses), I usually go to Tung Chung to visit a doctor, and it is very cheap in government hospitals. Tai $\mathrm{O}$ also has a family clinic. If your situation is too serious, they will have an ambulance to get you to larger hospitals".

\section{Sub-Theme: Limited Ability to Refurbish/Maintain Homes}

A few participants $(n=3)$ shared how they could refurbish their homes in some significant way. For example, one participant shared that he recently repaired his rooftop, "[I replaced] my iron house rooftop, which was ten years old or something like that [with] stainless steel. Before, the rooftop was made of iron. In the past year, it was replaced by stainless steel. In the past, I have to paint it frequently to avoid rust. Now I change to stainless steel. I am old. I spent money on it-hundreds of thousands [of HKD], from my savings. I did not ask for it (the money) from anywhere". 
Other participants mentioned that they would do regular maintenance, albeit the costs to do that, they noted, are increasing, as one participant shared, "one of the expenses is for renovation and maintenance fees of the house, like painting the house and repair wooden planks, which costs me a few thousand [HKD] dollars. It is quite expensive nowadays to fix the wooden planks, over a thousand [HKD] dollars every time, and only a few people will do that". Another participant (I4) shared how as they age, it is more difficult to do their repairs and maintenance, "you know, people living on the sea (boats) are very clever. They can make many things on their own. We make our own stilts. But now, you know, we are old now. Like my family, if my three children do not come back to help us, we are not able to do it. My husband is like their teacher and engineer; he teaches my sons to build the stilts. That's how we can make it. Yes. He is, more or less, good at building and repairing stuff, haha! When he was young, he could repair the stilts on his own. There is no way now because he is old".

\subsubsection{Theme: Social Support during Non-Disaster Times}

Almost all the participants shared how the sources of social support during nondisaster times were mostly from their family $(n=11)$ or the government $(n=10)$, with some participants mentioning the support from the third sector (specifically a local NGO) $(n=2)$. Social support can be categorized into four domains: "informational (information provided to another during a time of stress), instrumental (the provision of tangible goods and services or tangible aid), appraisal (the communication of information which is relevant to self-evaluation rather than problem-solving), and emotional support (the provision of caring, empathy, love, and trust)" [36] (p. 228).

\section{Subtheme: Family Social Support during Non-Disaster Times}

All but one of the participants shared how their family (specifically their adult children) was a social support source. The types of support received were primarily instrumental $(n=10)$ and, for some $(n=5)$, emotional.

Instrumental Support. The instrumental support was primarily financial support from their adult children. One participant shared, "yes, every time they (referring to her four children) come back, they will give me some money; they will also buy things for me. I spend very little in Tai O. We don't need expense in transportation. Those with higher income will offer us more money. We do not require them to give us". At the same time, a few participants $(n=3)$ mentioned they do not want to receive any financial help from their children, as one participant explained why, "but they have to support their households too. You have to be reasonable, right? The economy is bad now anyway. My sons don't really have decent jobs; they don't really earn a lot". One participant has no children of her own and shared how her nephew and his wife (who lives close to her in Tai O) provide instrumental support, "my nephew opens it (the store) for me, and I come to operate [and] my nephew's wife cooks for me. She only cooks once (the dinner). We have breakfast separately".

Emotional Support. In terms of emotional support, some participants $(n=5)$ shared how their adult children and grandchildren would come back to Tai $\mathrm{O}$ to visit and spend time with them. For instance, one participant shared, "I have a daughter and three grandchildren. The eldest grandchild always comes back and visits us. The other two grandchildren are still studying". However, most $(n=7)$ of them mention that the visits are often during the major festivals, as a participant explained, "yes! I have eight or nine great-grandchildren. But I don't see them much. Well, yes, they do come to see me. During the big festival, these children come to visit me to have a festival gathering dinner. Some of them would drive all the way back here to visit". A participant echoed this idea but also shared that she and her husband would travel to the city to visit her family as well, "usually yes. My grandchildren like going to Tai $\mathrm{O}$. They must come back during festivals. Sometimes we go out for dinner with my sons and their family. Normally I take the 5 p.m. 
bus to Hong Kong in Tsing Yi (which takes approximately $1 \mathrm{~h}$ and $45 \mathrm{~min}$ by bus) after working here, and I return to Tai $\mathrm{O}$ after dinner".

Support with family is a two-way street. A couple of the participants also shared how they have or continue to provide social support to their adult children or grandchildren. For instance, one participant mentioned how she helped to raise her grandchildren until they were ten years old, "my grandchildren have grown up here. They are all raised by me. My sons had to work. They left Tai $\mathrm{O}$ at about ten years old. They had to transfer to the schools in Hong Kong to catch up with the syllabus, and that is when I started to work again". Another participant mentioned how he and his wife helped to pay for their son's university tuition, "my wife is a temporary worker. She does not have a regular job. She works for around ten days each month. When the others have day-offs, she will take their places. She does cleaning, and her income does not help the family a lot, but we need to work hard to earn money; life needs money. University needs money too. It's more than HKD100,000 dollars (approximately USD13,000) for my son's degree. The government only provides around HKD30,000 (approximately USD4000) grant. We have raised them up already, so it's ok. We have not borrowed any loan to support him so that he will have less burden when in the future when he works. So that he will not have to repay for any debts".

\section{Subtheme: Government}

Instrumental Support. The government's primary support was financial support through the Old Age Allowance (OAA) scheme in Hong Kong, whereby all the participants were recipients. They explained how this social assistance was their primary source of income, as one participant shared, "yes, I have OAA, or else we could not sustain our living here. The subsidy of OAA will support us if we do not have enough income. There were days that we have no income generated from the shop. The unit price of every product sold is small. I have to sell a lot of drinks to get 200 to 300 (H.K.) dollars (approximately USD25-40) income".

Aside from OAA, which dominated the discussion around government support, a couple of participants also mentioned other programs. The Elderly Health Care Voucher Scheme-which enables older people 65+ an annual amount of HKD2000 to pay for fees related to outpatient services at designated clinics and hospitals-and the Transport Fare Concession Scheme for the Elderly and Eligible Persons with Disabilities-which enables older people 65+ to travel to any designation via public transport for HKD2 (approximately USD0.25) per trip-were sources of support. A participant explained the benefits of the transportation scheme: "sometimes I go to the city when it is a festival or special day. Like My birthday and my wife's birthday. Better than they, about 20 people, come back to Tai $\mathrm{O}$. The transportation is expensive. It cost my wife and me only HKD2 for transports. Just HKD4! You know, the economy is bad now; better save money, haha!" To give some background, the price of transport via public transport from Tai $\mathrm{O}$ to Tung Chung would be about HKD12 (approximately USD 1.54) per trip (round trip would be HKD24). Another participant had shared, "we could enjoy medical benefits and have Health Care Vouchers, I usually go to Tung Chung to visit a doctor, and it is very cheap in government hospitals. Tai $\mathrm{O}$ also has a family clinic. If your situation is too serious, they will have an ambulance to get you to larger hospitals".

\section{Subtheme: Non-Governmental Organizations}

A couple of the participants also shared how the local NGO plays a key role in providing social support. For instance, one participant mentioned how a local NGO provides emotional support through home visits, "I have regular home visits from them. They sometimes chat with me too. They are nice". Another participant even suggested that the same NGO is a key contributor to the quality of life for Tai $\mathrm{O}$ residents, as she shared, "only people from [Name of NGO]. If not, with the help from them, Tai O residence could not enjoy as many benefits as right now. They help us fight for our many benefits. I 
hope that they won't retreat their office in Tai O. [Name of NGO] was there 20 years ago, I remember they would hold different classes for adults like writing and bakery classes".

\subsection{Research Question \#3: How Do Disasters Implicate Aging in Place for These Residents?}

\subsubsection{Theme: Damages/Losses Related to Home and Work/Livelihood}

In recalling the impacts from the Super Typhoon Mangkhut-a Signal No. 10, the highest level of a tropical cyclone warning according to the Hong Kong Observatory, with wind speeds sustained at $250 \mathrm{~km} / \mathrm{hr}$-in September of 2018, most $(n=10)$ of the participants shared the damages and losses they incurred related to their homes and work. For instance, a participant shared, "it flooded my shop. The water level was this (point at the level-about $60-80 \mathrm{~cm}$ high) high. So, it drowned almost the whole shelf (referring to the shelf of goods being sold). Yes. It (the water) just flushed in because there was much rain. So, it was rain and water that flushed in together. There was some loss. Only the stock on the surface was not affected. I think I lost around HKD200 (approximately USD26). That's a lot of money!" Another participant shared how her home was significantly damaged, "the total amount of money I paid for replacing all furniture is around 20 to 30 thousand [H.K.] dollars (approximately USD2600 to 3900). There are many boards and panes that were broken in two".

A few participants $(n=3)$ also shared how the intensity of the disaster has increased in recent years. As one participant explained, "I have never experienced before (referring to the intensity of the storm surge and flooding from Super Typhoon Manghkut). I am eighty-something. I have experienced just two typhoons in the past like this. [Super Typhoon] Hato and Mangkhut. Yes, two times. It (referring to the water level) was reported 8 to 9 feet high. The board inside (his store/home) is not even higher than 8 to 9 feet. So, of course, last time, our place was flooded. In the past, typhoons did not cause flooding. It (referring to the intensity) was the happening in the recent typhoons. Very high at the front of the stilt house. We are of old age. We already had a lot of hard times". A couple of participants mentioned they did not incur any significant material losses. For instance, one participant shared, "only a small fridge was damaged, and it was very cheap".

\subsubsection{Theme: Disaster Preparedness Is Physically Taxing}

Most participants $(n=10)$ shared how their preparedness for a disaster focused primarily on protecting their material goods and household items from the flooding and storm surge. Preparedness would involve the participants lifting all the material goods and furniture from the ground to the upper floor once they received the typhoon's notification. For Super Typhoon Manghkut, they were notified the day before to evacuate. One participant shared, "and so, we were able to push the refrigerators to higher places at the back of this area and kept them safe there. We had thought the fridges here would not be affected, and we had thought that the ones inside the house would get soaked. And it turned out the ones inside got soaked. One refrigerator already cost over HKD3000 (approximately USD390), and I had to buy two new ones! Yes! That type of refrigerator is very big and tall, even taller than a person!"

A couple of participants shared how doing these disaster preparations would be a struggle they had been just by themselves. As one participant explained, "I am over 60+, couldn't lift up the fridge. No one [there to help]. I have to let it be flooded and move all the other things to the tabletop". While another participant shared, "I asked my children to come help elevate the bases (referring to the heavy items like refrigeration and washing machines) or take them upstairs. If they were busy and couldn't come help, I would just do it myself bit by bit slowly".

\subsubsection{Theme: Disaster Response and Recovery Is Physically Taxing}

The damages ranged for the participants, and most participants $(n=11)$, it took one day to a week to clean up. However, for one participant, the recovery period was much more extended as she voiced, "there is still some cleaning work outstanding right now. The 
panes below the stilt houses are damaged. I lost patience in cleaning it all up. So, it took me around 2 to 3 months". Regardless of how long the short-term recovery period took, most participants $(n=10)$ discussed how it was a physically and financially taxing process. One participant explained, "the whole cleaning is very troublesome! I did all the cleaning at night. I did it bit by bit, area by area. I switched on the fan and dry everything. I couldn't sleep! It's overnight work! All night through until 10 a.m. the next day. Slowly bit by bit. I couldn't even eat! Every time when typhoon attacks, life is like this. So I observe it. Two days. It only takes me two days [but] it's a non-stop kind of work!" Another participant also expressed how the cleaning up process was non-stop for her, "I had no choice but only managed it slowly. Those youngsters (referring to the volunteers and social workers of the local NGO) told me to stop working, but I had nothing else to do, so I just worked casually. I was so busy tidying the things that I could barely eat. I could not cook either".

\subsection{Research Question \#4: What Resources and Supports Do They Access and Use to Reduce Disasters' Impacts?}

3.4.1. Theme: Resources and Supports for Disaster Preparedness (Pre-Impact)

Regarding disaster preparedness, which includes risk communication and evacuation, the participants shared how the supports they access were from themselves, the third sector (e.g., NGOs), family, and civil service officers (e.g., police officers and firefighters). During this time, the type of support was primarily instrumental (e.g., assisting with carrying heavy household items to the second floor to mitigate the impacts of flooding) and informational (e.g., real-time updates of the disaster situation pre-impact).

\section{Sub-Theme: The Third Sector and Civil Service Officers' Key Role}

Moving Large Household Items to Higher Ground

Some participants $(n=5)$ shared how the third sector and civil service officers were instrumental in helping them move the large household items to higher ground to reduce the impacts from the flooding and storm surge from the typhoon. For instance, when asked about who was of most help to prepare for the disasters, one participant shared, "of course it is them (referring to NGOs and civil service officers) that provided the most aid. They are the professionals". Another participant (I14) shared how they were the first line of support, "the Civil Aid Service team and firefighters also checked with us before the typhoon much early, two days before, on and asked if we need help. They were the earliest people to offer help". One participant explained this support helped to minimize his losses significantly, "luckily the civil service officers helped me carry the refrigerator into the shop, so the refrigerator could still be used now. I was only able to relocate the other stuff at the front there (pointing to some household items) by myself, but the ones at the back were too heavy, I could not load it onto a safe place on my own. I cleared out the space and asked them to help relocate things for me. They helped us during the typhoon, so I only suffered a little financial loss during the typhoon, which is still acceptable".

Risk Communication and Evacuation

Regarding risk communication and evacuation, all the participants shared how the civil aid officers (e.g., firefighters and police officers), volunteers, and staff from the local community NGO were the primary and key sources that influenced their disaster preparedness or evacuation behavior and activities. For instance, a participant shared, "there were some Tai $\mathrm{O}$ residents and Civil Aid Service officials asking us to leave. There was a building that was not safe on the hillside, which might be collapsed. So, they asked everyone to leave. We either went to [local NGO] or the places provided by Tai O Rural Committee to sleep. Yes, also the social workers. They always tell us not to stay here and leave [and go the temporary shelter] (referring to the evacuation pre-impact). The night before, it came (Friday night). For example, [they would say] "it is typhoon signal no.8", and at the night before, they kept coming and checking. They are very nice. Yes, they knew the night before/It (technology) is so advanced now, those typhoons and people. They always keep 
updated about the situation of the typhoon. Yes, they always keep us updated, like they know when to tell us to leave [for typhoon]".

Aside from knowing about the typhoon through the radio or T.V., participants shared how staff from organizations would, personally, either come directly or phone to relay the information about the typhoon as another participant shared, "yes, there were many news reports. Yes, I knew it from [watching] the T.V., Yes, but also many people from the organizations helped [notify] me too. People from [organization A] in Tung Chung (the city) even phoned me. We have been keeping in touch".

A participant shared how this support was significant during her evacuation, "what I think is if there are no youngsters (referring to the NGO staff and volunteers) we are not able to do any evacuation on our own. That's not easy, you know. We are injury-prone anyway". A couple of the participants also shared a formal evacuation site where they stayed organized by the NGOs and civil service aid officers. As a participant explained, "it is prohibited to stay here (referring to his home). So I stayed [at the evacuation stie] for two nights, there was such great catering there! You cannot say worried or not, but if there is another strong typhoon, I will just go to the temporary shelter in Lung Tin Estates. It is the best [safest] there". However, a participant shared how the arrangement of the beds in the evacuation sites was not particularly age-friendly, "I was sleeping all the time in the [evacuation site] and didn't do much. There were four beds in one unit-that's two bunk beds per unit. There were a kitchen and toilet. It was inconvenient for the older people to sleep on the upper deck, so we asked the younger ones to sleep on the upper deck".

\section{Sub-Theme: Family Support Limited during This Phase}

Half of the participants $(n=6)$ shared how their family played a supportive role during the preparedness phase, especially in helping the older adults lift heavy items to higher ground to mitigate the damages caused by the flooding and storm surges. Other participants $(n=4)$ shared how their family support was limited due to the physical distance (e.g., family living in the city) and lack of time (e.g., busy with work). For those older adults who had family living in Tai $\mathrm{O}$, the family members were the first line of support, as one participant mentioned, "my nephew and his wife, mainly was here to help me". A couple of participants, whose families lived in the city, shared how their adult children helped them. As one participant said, "I asked my children to come to help elevate their bases (referring to the heavy household items) or take them upstairs". At the same time, he continued to share, "if they were busy and couldn't come help I would just do it myself bit by bit". The family support was also limited by the lack of real-time knowledge and information about the disaster risks compared to the civil service officers and NGOs. As one participant mentioned, "they (referring to her adult children) didn't know that (referring to the intensity of the typhoon) at the beginning. You never know how the typhoon would be before it actually happens. They didn't know how terrible it would be. They just knew it from the television".

\section{Sub-Theme: Self-Reliance}

All the participants discussed how they contributed to disaster preparedness in various ways, including using knowledge from their experiences with previous disasters and physically moving household items to elevated grounds or placing sandbags to reduce the floods' impacts. For instance, one participant shared how their home was less flooded due to the preventative measures they took, "no, our house was not that flooded. We used sandbags to block it. If we do not block it, the flood would flush into the house". In contrast, another participant mentioned how the sandbags were useless to prevent flooding in their homes, "no, the wind speed was too strong that the sandbags were useless. If a typhoon hits again, there are some sheds outside, and I will tie them to the hook right here for support. This is the flood barrier installed by myself. It costs me 10,000 [H.K.] dollars (approximately USD1290), but the cost is inevitable, I am too old, and no other 
people could offer help when the flooding hits again as people have to take care of their own family as well".

Importantly, some participants $(n=4)$ mentioned that while the civil service officers or volunteers offered help, they refused that help because they felt they could do it themselves or others were in more need. For example, a participant explained that he and his wife did all the disaster preparedness, "yes, no one helped us. We did it all ourselves. There were some volunteer workers, but I didn't ask them for help because I could do this by myself". This sentiment of self-reliance is echoed in another participant, "in the end we have to count on ourselves as every family is busy in taking care of themselves. We have to help ourselves too". Another participant (I3) shared how he was focused on ensuring his boat was safe from impact, "the boat was all right. I was here, and I kept it safe. I used the ropes to attach it to the stilt firmly. The only thing I worried about was the water which could swallow the boat away. So, it was attached very firmly by four ropes".

Some participants $(n=4)$ also shared how their prior experiences with disasters, specifically with more intense disasters such as Typhoon Hato-another super typhoon that occurred in August 2017-influenced their disaster preparedness activities. For instance, a participant explained, "after Hato, we learned that we should be prepared for strong typhoons, so we put the electric appliances on the racks. We learned a lesson from Hato. After Hato, my fridge and washing machine were damaged".

\subsubsection{Theme: Resources and Supports for Disaster Response and Recovery}

Regarding disaster response and recovery, the participants shared how the supports they accessed and used were from the third and private sector $(n=10)$, government $(n=10)$, themselves $(n=10)$, and family $(n=7)$. The support during this time was primarily instrumental (e.g., financial assistance from the government or private sector, replacement of household items (e.g., washing machines) from the NGOs).

\section{Sub-Theme: The Third Sector Plays Key Role in Recovery}

Most of the participants $(n=10)$ shared how the NGOs played a key role in providing instrumental support (including financial compensation, replacing or fixing large household items that were damaged, and to some extent, helping to clean the homes) in their recovery process from Typhoon Mangkhut.

Financial Compensation

Almost all participants $(n=11)$ shared how they received financial compensation from an NGO of 3000HKD (approximately USD390), and no registration was needed to receive this. One participant shared how financial support was given not only after Mangkhut but in previous disasters as well, "the peak (an NGO located at the upland of Tai O) gave some subsidies. Subsidies were given every time it was flooded. I was also given several thousand [HKD] dollars subsidies for compensation and support. Every household is given 3000 [HKD] in here for floods. They distribute money and blankets and things like that to help. They know that you are really in need and are impacted by the floods. They give you the money and the things for support-no need to register".

Albeit a few participants $(n=3)$ mentioned that the compensation was not sufficient, as one participant explained, "they didn't care how much we have lost. They gave a fixed amount to each household, even though we lost things that were worth 10,000 [H.K.] dollars (approximately USD1290)". Though some participants $(n=4)$ shared how they knew this amount was only meant for basic/urgent care needs, as one participant said, "the peak got us 3000 [HKD] — that was urgent survival money". While most of the participants $(n=8)$ received 3000HKD [approximately USD390], a couple of participants $(n=2)$ shared they received additional financial compensation from other charities/NGOs. As one participant mentioned, "sometimes corporations in Hong Kong donates and covers [for us]. The big corporations gave 8000 [HKD] to each household. They donated a 20,000 [HKD] (approximately USD2580) cheque to me. The Rural Committee arranged for me and got it from there". 
Non-Financial Support

Aside from the financial compensation, all the participants shared how non-monetary support from the NGOs was also instrumental in their recovery process. For instance, a participant shared, "after [the] typhoon (Mangkhut), Mr. [the social worker] helped us to record our loss and register the application for compensation for us. He helped with locating second-hand electric appliances to be replaced". Another shared how the staff at the NGO helped with various tasks that were significantly helpful to her and her husband with mobility issues, "they (volunteers and staff from the NGO) drove my husband and me back. He is unable to walk, and the way back home from the YWCA was tough for me too. They also helped me to order and deliver those appliances here. It is so exhausting if it was just me. Also, they helped to bring us food to eat during this time".

While the NGOs seldom gave financial support, their help was nonetheless essential as a participant said, "they are helpful. They seldom give money. Instead, if you say you are short of a particular thing, and they will try their best to find you one. The most important is they can provide what I need, like how the NGO helped me replaced my refrigerator". One participant shared how this type of support provided by the NGOs was more important than financial compensation, "it's (referring to the financial compensation) useless! We have to clean up all the mess after every strong typhoon! We have to work even there is more compensation, you know! More preparation is better than more compensation". Half of the participants $(n=6)$ shared how the NGOs reached out to them personally to assess their needs. For example, one participant said, "some social workers visited us and offered help. Although we have, (financial) compensation received but we don't always want to buy a new one (referring to household items damaged). The social workers know how to help us fix it instead". The relationship between the local NGO and older people was further relayed by a couple of participants, as one said, "many people from the [name of local NGO] helped. Yes. They know well about the community here. Yes, they are very nice. They also gathered some volunteers from Hong Kong. They sent us second-hand electric appliances and helped clean the mess up".

However, a couple of participants mentioned some limitations of the NGOs' support. For instance, one participant how they are still awaiting assistance in replacing the damaged wood flooring, I have already waited to replace the wood flooring for a long period of time after the typhoon. They (the NGO) are also waiting for a sponsor [financially], then they could help. If they do not have money, they could not provide support. I am waiting [and] the next typhoon is coming. But they haven't yet fixed it for me. Therefore, they are waiting for the sponsor".

\section{Sub-Theme: Government Support Limited}

Most of the participants $(n=9)$ expressed that the governments' support was limited in that they only provided financial support. Furthermore, half of the participants $(n=6)$ did not access such support as it was too challenging/troublesome to apply and register for it. One participant recalled how the government provided financial compensation for typhoon Mangkhut and also for previous disasters, "yes, I remember, it was around 2000 to 3000 [H.K.] dollars (approximately USD260 to 390). Yes, they provide compensation before, but it doesn't really cover the actual cost. [For example] to replace a new refrigerator, I had to supplement with some money of my own". Half of the participants $(n=6)$ shared how even though they were eligible for the compensation, they did not apply. As one participant explained, "no, I didn't apply, it is very troublesome to apply; it requires a lot of things that are very annoying. I did not want to apply". She also shared how she didn't apply and further expressed her discontent that no one asked about their emotional/mental well-being, "no, we didn't apply for any compensation. No, not at all. We couldn't. We are not good at documenting things like these. You know, no one asked us 'how are you after the typhoon?'-no one". 
Sub-Theme: Family Support during This Time Is Limited

Some participants $(n=4)$ shared how their family provided instrumental support to them during the recovery process. For instance, one participant mentioned how she did not apply for the government compensation because she asked her son to come help fix the damages to their home, "I didn't apply, because I can work on it on my own [and] with my son. And we have stock of wooden materials". Another participant shared how her children helped during this time, "my children did come back and help out. They mainly helped me with the larger furniture, like removing the refrigerator. They also helped to fix the sheds on the stilts". However, another participant shared how her family help was limited due to the physical distance, "no, they couldn't help. If they come here, they could not go back. You know, the transport of Tai O. Traffic jam. The tree. During the typhoon, there are no cars. They are afraid, and they do not come back. Someone would take care of me here. They would not come back. It was heavy raining here. All left. We also found the shelter".

\section{Sub-Theme: Self-Reliance and Difficult to Ask for Help}

Almost all participants $(n=11)$ shared how they relied on themselves during the recovery process because they felt they did not want to bother others. It was difficult to ask for help or felt that others were in more need. For instance, one participant took about a week to clean up after Mangkhut and could not attend to her livelihood, "I spent an entire week fixing everything! I lost a week's income from my business. What could I do? I live in Tai O. I don't live elsewhere. Elsewhere is definitely in a better situation. Life in here [during Typhoon] is difficult. It's also difficult to ask for help from other people". Another participant shared how the NGOs and civil service officers offered help, but he refused, "we didn't need any help here because nothing much is broken, so we didn't bother them".

\subsubsection{Theme: Resources and Support for Mitigation}

Only half of the participants mentioned resources and supports for mitigation. Most of the discussion focused on the infrastructure that was built by the government to reduce the impacts of floods. Specifically, it was related to the flood protection gates on a main street in the village. A few of the participants $(n=3)$ mentioned that the gates were not helpful to reduce the impacts of the floods, specifically of the stilt homes, as one participant explained, "the barriers are useless. It is effective for the houses near [Street Name]. The two sides of the houses were blocked so the water couldn't get in. But the stilt houses suffer even more, as the water couldn't be diverted away, more water flooded into our stilt houses [on] this side. If the government could spend more on prevent flooding, the situation could be greatly relieved. Two more barriers should be built at the two sides at [location 1] and [location 2]. Yes, there are many people now living in stilt houses that should be protected. The people living in the stilt houses suffered badly. They have a long history established in Tai O, around 100 to 200 years of history". Other participants shared how resources and support are needed to maintain the stilt houses. As one participant noted, "I hope they can understand what loss I have faced and provide relevant help. I don't ask for compensation. I only suffered relatively smaller loss. Other people suffer more. They need more help and support. It will be better if they provide subsidies for our stilt's [homes] maintenance. That kind of support is different. It does help! Like they can help with adding the paint on my stilt...sometimes they can help replace my boards when they get weathered and rotten".

\section{Discussion}

This study explored the experiences and perspectives of AIP among older people living in a disaster-prone rural coastal community in Tai $\mathrm{O}$ Village, Hong Kong. In this section, I discuss several key and unique findings in relation to existing literature and recommend next steps in terms of research and practice.

First, the findings suggest that a critical dimension of AIP for the older adult residents in Tai $\mathrm{O}$ is their ability to sustain and continue their work, which played a multidimen- 
sional role and not simply for income purposes. For example, their work seemed to be primarily an activity that contributed to their mental well-being or "inner sustenance" and was particularly important to do as they continue to age. Furthermore, their work was a form of social participation that enabled them to engage with their neighbors and others in the community. This finding is significant because there are relatively little discourse and research that examines how AIP is connected to supporting older people in maintaining their work as they age, especially those who are low-income. Future research and practice should examine the role of work in supporting AIP. In rural coastal communities, this means the traditional livelihoods they have been engaged in throughout their lives. Importantly, flexibility and independence (e.g., working on their terms, work hours) are key characteristics of work/livelihoods that the older residents favor. This finding is aligned with human resources literature regarding older workers' engagement [37]. Importantly, older adults' perspectives should be engaged in the development of work programs. Such programs should be reflective of the range of interest, needs, and skill sets of older adults with diverse work histories. Second, the findings suggest that local community-based organizations play an instrumental role in providing social support in a disaster context (specifically in risk communication, disaster preparedness, response, and short-term recovery) for the older residents. The findings highlighted that the local CBOs were the first line of response when a disaster had struck, as family members often lived in the city. This finding is significant as it highlights how local CBOs are vital stakeholders in supporting AIP through day-to-day regular social participation and well-being activities and that such CBOs can be activated in disaster situations. In this study, the local CBO was already a part of an Age-Friendly Communities Initiative launched in 2017 to build trust and rapport with older adult residents and lay the foundation for the CBOs to be activated in disaster situations. This highlights how initiatives such as AFC at the same time can contribute to disaster risk reduction initiatives as well. The local CBOs must have the knowledge, skills, and experience to support older adults throughout a disaster situation. Future research and practice should focus on connecting AFC or AIP initiatives with disaster risk reduction. For instance, this may include building the CBO's disaster knowledge and roles in supporting older residents. In particular, the findings suggest that there lacked emotional support during the post-disaster recovery period, and providing psycho-social support during this phase is another focal point of examination. As climate-related disasters continue to grow in intensity and frequency, the local CBO's disaster knowledge and capacities are even more critical in supporting older residents in rural coastal communities. Furthermore, disasters may also include such contexts as the current COVID-19 pandemic. Such disaster knowledge, skills, and experience are transferable in reducing the pandemic's risks and negative impacts.

Third, the findings highlight that while there are resources and supports available to older adults during the disaster preparedness, response, and (short-term) recovery phases of a disaster, more support and resources for mitigation activities are needed. This finding is aligned with literature highlighting that "little attention is paid to resiliencebuilding efforts during the mitigation phase, despite this phase being a critical point of intervention" [38] (p. 1). Mitigation is a crucial phase to reduce the negative impacts of disasters, as they are strategies and activities that are more preventative than reactive. Furthermore, this phase highlights the deep connections between day-to-day structures and processes and an individual, community, and society's capacity to adapt and reduce disasters' negative impacts. Social, political, economic, and environmental/infrastructural systems that support older adults' health and well-being (which include their capacity to AIP) in their daily lives also help to support older adults in disaster situations. The finding above highlights the importance of mitigation efforts in disaster situations, as the local CBOs played a crucial role in helping the older residents. Future research and practice should focus on assessing and developing the social, economic, political, and physical infrastructures of disaster-prone rural coastal communities. They are often neglected in broader development initiatives. At the same time, as sea levels continue to rise and low- 
lying coastal communities are the most vulnerable to such conditions (IPCC, 2019), research and practice will also need to include a focus on relocation/resettlement efforts (inland) as part of a mitigation strategy. Importantly, these relocation/resettlement efforts must prioritize the principles of AIP, so that the new location and community is also perceived by the older residents as an age-friendly place.

Lastly, the findings highlight that while supports exist for AIP and in a disaster situation, the older residents may not utilize such supports. An exemplar of this was the financial supports, which many of the participants were eligible for but did not apply. Furthermore, some participants mentioned that they would rather repair their damaged goods than use the money to purchase new ones or that they needed people physically supporting them in the recovery and building-back phases rather than the money (e.g., cleaning the home after the typhoon). This finding suggests that such supports should be provided in a way that considers older peoples' orientation towards self-reliance and difficulties in asking for help. This finding is important as it highlights how AIP and disaster risk reduction activities and programs should be shaped (e.g., prioritizing capacity building and self-efficacy of older adults) and marketed. Future research should explore why older adults seek help or not and the forms of support offered in disaster situations; this will help inform how service providers can approach and support older adults in diverse ways.

\section{Limitations and Conclusions}

The small sample size limits the findings to be generalized to the broader older adult population living in disaster-prone rural coastal communities. Statistical generalization, that is, drawing inferences from data to a population, cannot be made from this single case study. However, analytical generalizations may still be made and are helpful in developing theory or evaluating the transferability of findings to similar cases and contexts [39]. Additionally, the sample was primarily married participants; thus, this may have limited a deeper understanding of the unique needs and challenges of older adults who are single or widowed. Marital status is a factor as it has been correlated in some studies with less favorable disaster-related outcomes among older adults [40-42]. Future studies should focus on AIP and disaster resilience of single/widowed and low-income older adults living in disaster-prone rural coastal communities, as they are an at-risk group.

Societies are experiencing rapidly ageing populations and increasing intensity and frequency of disasters that bring forth challenges and possibilities (Kwan and Walsh, 2017). Rural coastal communities with ageing populations are at a heightened risk of experiencing (and already do experience) the negative impacts of disasters, which in turn impact their capacity to AIP. This study highlighted the intricate connections between AIP and disasters, particularly in rural coastal communities. However, the COVID-19 pandemic has shown that being disaster-prepared should be a priority for all societies and communities. Thus, AIP discourse and practice need to explicitly integrate a dimension of understanding AIP within the context of disasters.

Author Contributions: Conceptualization, C.K.; methodology, C.K. and H.C.T.; formal analysis, C.K. and H.C.T.; investigation, C.K. and H.C.T.; resources, C.K.; data curation, C.K.; writing-original draft preparation, C.K. and H.C.T.; writing-review and editing, C.K. and H.C.T.; supervision, C.K.; project administration, C.K.; funding acquisition, C.K. Both authors have read and agreed to the published version of the manuscript.

Funding: This research received no external funding.

Institutional Review Board Statement: The study was conducted according to the guidelines of the Code of Ethics for Research Involving Human Subjects, and approved by the Institutional Review Board of the Hong Kong Polytechnic University (Reference \#HSEARS20190502001).

Informed Consent Statement: Informed consent was obtained from all subjects involved in the study. 
Data Availability Statement: The data presented in this study are available on request from the corresponding author. The data are not publicly available due to privacy/confidentiality of the participants.

Conflicts of Interest: The authors declare no conflict of interest.

\section{References}

1. United Nations. World Population Ageing 2019 (Report No. ST/ESA/SER.A/430). 2019. Available online: https://www. un.org/en/development/desa/population/publications/pdf/ageing/WorldPopulationAgeing2019-Report.pdf (accessed on 3 January 2021).

2. Astill, S. Ageing in remote and cyclone-prone communities: Geography, policy, and disaster relief. Geogr. Res. 2017, 55, 456-468. [CrossRef]

3. Bayliss, J.; Sly, F. Ageing across the U.K. Reg. Trends 2010, 42, 2-28. [CrossRef]

4. Krawchenko, T.; Keefe, J.; Manuel, P.; Rapaport, E. Coastal climate change, vulnerability and age friendly communities: Linking planning for climate change to the age friendly communities agenda. J. Rural Stud. 2016, 44, 55-62. [CrossRef]

5. Zhang, X. The aging trend analysis for the rural coastal zone in Shanghai. In Proceedings of the 2011 International Conference on Business Management and Electronic Information, Guangzhou, China, 13-15 May 2011; Volume 4, pp. $702-709$.

6. Wiles, J.L.; Leibing, A.; Guberman, M.N.; Reeve, J.; Allen, R.E.S. The Meaning of “Aging in Place” to Older People. Gerontologist 2011, 52, 357-366. [CrossRef]

7. Lawton, M.P.; Simon, B. The ecology of social relationships in housing for the elderly. Gerontologist 1968, 14, 108-115. [CrossRef]

8. Lawton, M.P.; Nahemow, L. Ecology and the Aging Process. In the Psychology of Adult Development and Aging; Eisdorfer, C., Lawton, M.P., Eds.; American Psychological Association: Washington, DC, USA, 1973; pp. 619-674.

9. Lawton, M.P. Environment and aging: Theory revisited. In Environment and Aging Theory: A Focus on Housing; Scheidt, R.J., Windley, P.G., Eds.; Greenwood Press: Westport, CT, USA, 1998; pp. 1-31.

10. Vasunilashorn, S.; Steinman, B.A.; Liebig, P.S.; Pynoos, J. Aging in Place: Evolution of a Research Topic Whose Time Has Come. J. Aging Res. 2011, 2012, 1-6. [CrossRef] [PubMed]

11. Jurjonas, M.D. A Framework for Rural Coastal Community Resilience: Assessing Diverse Perceptions of Adaptive Capacity for Climate Change. Ph.D. Thesis, North Carolina State Univiersity, Raleigh, NC, USA, 2018.

12. International Institute of Rural Reconstruction (IIRR). Participatory Methods in Community-Based Coastal Resource, Volume 1 Introductory Papers; International Institute of Rural Reconstruction: Silang, Philippines, 1998.

13. Kapucu, N.; Hawkins, C.V.; Rivera, F.I. Disaster Preparedness and Resilience for Rural Communities. Risk Hazards Crisis Public Policy 2013, 4, 215-233. [CrossRef]

14. Government of United Kingdom (GovUK). An Evidence Summary of Health Inequalities in Older Populations in Coastal and Rural Areas. 2019. Available online: https://assets.publishing.service.gov.uk/government/uploads/system/uploads/attachment_ data/file/824723/Health_Inequalities_in_Ageing_in_Rural_and_Coastal_Areas-Full_report.pdf (accessed on 3 January 2021).

15. Intergovernmental Panel on Climate Change (IPCC). Sea level rise and implications for low-lying islands, coasts and communities In Special Report: Special Report on the Ocean and Cryosphere in a Changing Climate; Weyer, N.M., Ed.; Intergovernmental Panel on Climate Change: Geneva, Switzerland, 2019; pp. 321-445.

16. Jurjonas, M.; Seekamp, E. Rural coastal community resilience: Assessing a framework in eastern North Carolina. Ocean Coast. Manag. 2018, 162, 137-150. [CrossRef]

17. Barbier, E.B. Climate Change Impacts on Rural Poverty in Low-Elevation Coastal Zones. Estuar. Coast. Shelf Sci. 2015, 165, A1-A13. [CrossRef]

18. Astill, S.; Miller, E. 'The trauma of the cyclone has changed us forever': Self-reliance, vulnerability and resilience among older Australians in cyclone-prone areas. Ageing Soc. 2016, 38, 403-429. [CrossRef]

19. Bukvic, A.; Gohlke, J.; Borate, A.; Suggs, J. Aging in Flood-Prone Coastal Areas: Discerning the Health and Well-Being Risk for Older Residents. Int. J. Environ. Res. Public Health 2018, 15, 2900. [CrossRef] [PubMed]

20. Kwan, C.; Walsh, C.A. Seniors' disaster resilience: A scoping review of the literature. Int. J. Disaster Risk Reduct. 2017, 25, 259-273. [CrossRef]

21. Coetzee, C.; van Niekerk, D. Tracking the evolution of the disaster management cycle: A general system theory approach. J. Disaster Risk Stud. 2012, 4, 1-9. [CrossRef]

22. United Nations Office for Disaster Risk Reduction (UNDRR). Sendai Framework for Disaster Risk Reduction 2015-2030. 2015. Available online: https://www.undrr.org/publication/sendai-framework-disaster-risk-reduction-2015-2030 (accessed on 5 January 2021).

23. Stake, R.E. The Art of Case Study Research; Sage Publications: Thousand Oaks, CA, USA, 1995.

24. Merriam, S.B. Qualitative Research and Case Study Applications in Education; Jossey-Bass Publishers: San Francisco, CA, USA, 1998.

25. Islands District Council (IDC). Paper T\&TC 55/2019. In Minutes of Meeting of Traffic and Transport Committee 22 July 2019. Available online: https://www.districtcouncils.gov.hk/island/doc/2016_2019/en/committee_meetings_minutes/TTC/ TTCmin0722.pdf (accessed on 5 January 2021).

26. Government of Hong Kong Special Administrative Region (GovHK). Preventing Coastal and Low-Lying Locations from Being Affected by Storm Surges and Flooding. 2018. Available online: https://www.info.gov.hk/gia/general/201810/24/P201810240 0648.htm (accessed on 5 January 2021). 
27. GovHK. Hong Kong Poverty Situation Report 2019. 2020. Available online: https://www.statistics.gov.hk/pub/B9XX0005E201 9AN19E0100.pdf (accessed on 5 January 2021).

28. De Silva, M.; Kawasaki, A. Socioeconomic Vulnerability to Disaster Risk: A Case Study of Flood and Drought Impact in a Rural Sri Lankan Community. Ecol. Econ. 2018, 152, 131-140. [CrossRef]

29. Sixsmith, J.; Fang, M.L.; Woolrych, R.; Canham, S.; Battersby, L.; Ren, T.H.; Sixsmith, A. Ageing-in-Place for Low-Income Seniors: Living at the Intersection of Multiple Identities, Positionalities, and Oppressions. In The Palgrave Handbook of Intersectionality in Public Policy; Hankivsky, O., Jordan-Zachery, J.S., Eds.; Palgrave Macmillan: London, UK, 2019; pp. 641-664.

30. White, G.; Singh, T.; Caine, K.; Connelly, K. Limited but satisfied: Low SES older adults experiences of aging in place. In Proceedings of the PervasiveHealth'15: Proceedings of the 9th International Conference on Pervasive Computing Technologies for Healthcare, Istanbul, Turkey, 20-23 May 2015; pp. 121-128.

31. GovHK. Table 1A: Population by Sex and Age Group. Census and Statistics Department. 2021. Available online: https: //www.censtatd.gov.hk/en/web_table.html?id=1A\&download_csv=1 (accessed on 5 January 2021).

32. GovHK. Hong Kong Annual Digest of Statistics. Census and Statistics Department. 2020. Available online: https://www. censtatd.gov.hk/en/data/stat_report/product/B1010123/att/B10101232020AN20B0100.pdf (accessed on 5 January 2021).

33. Clarke, V.; Braun, V. Thematic analysis. J. Posit. Psychol. 2017, 12, 297-298. [CrossRef]

34. Braun, V.; Clarke, V. Using thematic analysis in psychology. Qual. Res. Psychol. 2006, 3, 77-101. [CrossRef]

35. Creswell, J.; Creswell, J.D. Research Design: Qualitative, Quantitative, and Mixed Methods Approaches, 5th ed.; SAGE Publications: Thousand Oaks, CA, USA, 2018.

36. Muñoz-Laboy, M.; Severson, N.; Perry, A.; Guilamo-Ramos, V. Differential Impact of Types of Social Support in the Mental Health of Formerly Incarcerated Latino Men. Am. J. Mens Health 2014, 8, 226-239. [CrossRef]

37. Heisler, W.; Bandow, D. Retaining and engaging older workers: A solution to worker shortages in the U.S. Bus. Horizons 2018, 61, 421-430. [CrossRef]

38. Kwan, C. Factors and processes in the pre-disaster context that shape the resilience of older women in poverty. Int. J. Disaster Risk Reduct. 2020, 48, 101610. [CrossRef]

39. Mills, A.; Durepos, G.; Wiebe, E. Encyclopedia of Case Study Research. In Encyclopedia of Case Study Research; SAGE Publications: Thousand Oaks, CA, USA, 2010; pp. 21-23.

40. Kohn, R.; Levav, I.; Garcia, I.D.; Machuca, M.E.; Tamashiro, R. Prevalence, risk factors and aging vulnerability for psychopathology following a natural disaster in a developing country. Int. J. Geriatr. Psychiatry 2005, 20, 835-841. [CrossRef]

41. Lin, M.; Huang, W.; Huang, C.; Hwang, H.; Tsai, L.; Chiu, Y. The impact of the Chi-Chi earthquake on quality of life among elderly survivors in Taiwan-A before and after study. Qual. Life Res. 2002, 11, 379-388. [CrossRef] [PubMed]

42. Pietrzak, R.H.; Southwick, S.M.; Tracy, S.; Galea, F.H. Posttraumatic stress disorder, depression, and perceived needs for psychological care in older persons affected by Hurrican Ike. J. Affect. Disord. 2012, 138, 96-103. [CrossRef] [PubMed] 